\title{
Local non-viral gene delivery of apoptin delays the onset of paresis in an experimental model of intramedullary spinal cord tumor
}

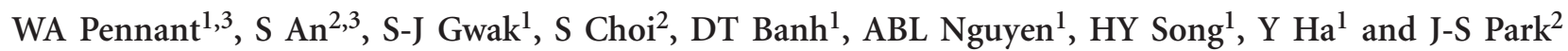

Objective: The objective of this study is to evaluate the safety and efficacy of a tumor-specific apoptosis-inducing gene, apoptin, as delivered by the non-viral carrier, PAM-RG4, in an animal model of spinal cord tumor.

Methods: Male Sprague-Dawley rats were given a 2.5- $\mu$ intramedullary injection of C6 glioma (100000) cells and randomized into three groups (day 0). On day 5, animals received a 7.5- $\mu$ I intramedullary injection of Dulbecco's modified Eagle's medium (Group 1; $n=7$ ), PAM-RG4/control gene polyplex (Group 2; $n=7$ ), or PAM-RG4/apoptin gene polyplex (Group 3; $n=8$ ). Hindlimb functional strength was assessed every other day for the duration of the study. The spinal cords of killed animals were collected and hematoxylineosin stained.

Results: Following treatment, animals that received apoptin had significantly higher mean functional hindlimb scores than those of sham control animals, showing a level of preserved hindlimb function throughout the study. In addition, Group 1 (sham control) and Group 2 (control gene) animals had median survival scores lower than those of animals receiving apoptin. Histopathological analysis showed marked retardation of tumor progression in apoptin-treated animals compared with sham controls.

Conclusion: Our study suggests that apoptin is safe for use in the mammalian spinal cord as well as effective in slowing the progression of tumor growth in the spinal cord. The significant slowing of tumor progression, as manifested by the preserved hindlimb function, coupled with the reduction in tumor volume, shows local non-viral delivery of apoptin could serve as an emerging therapy for the treatment of intramedullary spinal cord tumors.

Spinal Cord (2014) 52, 3-8; doi:10.1038/sc.2013.106; published online 5 November 2013

Keywords: apoptin; gene delivery; intramedullary spinal cord tumor; non-viral; PAM-RG4

\section{INTRODUCTION}

Intramedullary spinal cord tumors (IMSCT) are relatively rare neoplasms of the central nervous system (CNS), comprising $4-10 \%$ of CNS tumors. ${ }^{1}$ Surgical debulking of the tumor is the current accepted treatment of benign, well-circumscribed IMSCT. $^{2-5}$ However, the prognosis for patients with malignant lesions remains discouraging, owing to the high recurrence rate and the rapid and progressive infiltration of the spinal cord parenchyma that underlies clinical morbidities associated with malignant IMSCT. As such, no optimal treatment has yet been determined; ${ }^{5-7}$ thusly, the role of postoperative adjuvant therapy ever increases. Although some studies report benefits from the use of radiation therapy as part of the therapeutic regimen, ${ }^{8-12}$ concerns remain about the effect of radiation on children. Moreover, chemotherapeutic management of IMSCT has its supporters, ${ }^{13-17}$ but not enough studies have been done to support a field-wide consensus.

Given the limited role of such treatments, gene therapy continues to unfold as an attractive means of treatment in pre-clinical models of CNS tumor disease. Whereas there are numerous brain-tumor models that have tested the use of gene therapy, only two reports have been published looking at the use of gene therapy against an experimental intramedullary glioma. ${ }^{18,19}$ In an effort to clarify the role and possibilities of gene therapy against IMSCT, we decided to investigate apoptin, the gene product from chicken anemia virus $(\mathrm{CAV})$, in combination with the non-viral gene delivery carrier PAMRG4. Apoptin induces apoptosis selectively in malignant and transformed cells, ${ }^{20-22}$ whereas PAM-RG4, known for its high transfection efficiency and low cytotoxicity, was chosen to synergize the therapeutic effect in combination with the protein.

Apoptin, a 13.6-kDa protein, is responsible for the apoptotic activity of the CAV virus, ${ }^{21}$ which was previously fully characterized. ${ }^{20}$ Apoptin selectively induces apoptosis in human transformed and malignant cells, but not in normal cells, ${ }^{22}$ and in subsequent experiments this has been borne out, as apoptin has been shown to induce apoptosis in lung carcinoma, osteosarcoma, hepatoma, squamous cell carcinoma and breast cancer cell lines. ${ }^{23-26}$ The mechanism that enables the protein's selectivity has not been fully elucidated yet, but it is recognized that apoptin acts independently of

\footnotetext{
${ }^{1}$ Spine and Spinal Cord Institute, Department of Neurosurgery, Yonsei University College of Medicine, Seoul, Republic of Korea and ${ }^{2}$ Department of Chemistry, Seoul National University, Seoul, Republic of Korea

3These two authors contributed equally to this work.

Correspondence: Dr Y Ha, Department of Neurosurgery, Yonsei, University College of Medicine, 50 Yonsei-ro, Seodaemoon-gu, Seoul 120-752, Republic of Korea.

E-mail: hayoon@yuhs.ac

or Professor J-S Park, Department of Chemistry, Seoul National University ,599 Gwanak-ro, Gwanak-gu, Seoul 151-747, Republic of Korea.

E-mail: pfjspark@plaza.snu.ac.kr
}

Received 7 February 2013; revised 18 July 2013; accepted 6 August 2013; published online 5 November 2013 
$\mathrm{p} 53^{27}$ and that its translocation from the cytoplasm into the nucleus, as well as the activity of Nur-77, is integral to its ability to act. ${ }^{28-30}$ We hypothesized that local gene delivery of apoptin against an experimental IMSCT could be efficacious. In the current study, we tested the safety of apoptin injected into the body of the rat spinal cord via PAM-RG4. Owing to safety concerns regarding this polymer, the toxicity of an analog of PAM-RG4, ePAM-R, was also evaluated in vivo, as it was reported to be more biodegradable ${ }^{31}$ due to the ester bond that links arginine residues to the dendrimer. Afterward, we studied whether intramedullary apoptin could delay the onset of functional paresis in animals challenged with a malignant intramedullary C6 glioma.

\section{MATERIALS AND METHODS}

\section{Cell and animal preparation}

Rat C6 glioma cells (ATCC, Manassas, VA, USA) were maintained in the laboratory in Dulbecco's modified Eagle's medium (DMEM) with $4.5 \mathrm{gl}^{-1}$ of glucose, supplemented with $10 \%$ heat-inactivated fetal bovine serum and $1 \%$ penicillin/streptomycin at $37^{\circ} \mathrm{C}$ in a humidified atmosphere containing $5 \%$ $\mathrm{CO}_{2}$. The cells were maintained in T75 cell culture flasks and serially subcultured every 3 days using trypsin/EDTA. Tumor suspensions were prepared by suspending 100000 cells in 2.5 or $5 \mu \mathrm{l}$ of DMEM. Male Sprague-Dawley (SD) rats (Orient Bio Inc., Gyeonggi, Korea) weighing 250$300 \mathrm{~g}$ were properly housed in standard facilities and given liberal access to water and rodent chow. Each animal was treated in accordance with the policies and procedures of the Animal Care and Use Committee of the Yonsei University College of Medicine.

\section{Polyplex preparation}

PAM-RG4, in the form of a white powder, was first dissolved in DMEM to a total concentration of $20 \mathrm{mg} \mathrm{ml}^{-1}$. Polyplexes were prepared by mixing PAMRG4 with the apoptin gene at a 4:1 weight ratio. The complex solution was then allowed to stand for $30 \mathrm{~min}$ at room temperature and subsequently injected. All genes were complexed with PAM-RG4 prior to injection. The same method applies to the complex formation between ePAM-R and apoptin.

\section{Toxicity study}

Twenty-five male SD rats were randomized into five experimental groups $(n=5)$. The first group received a $5-\mu l$ intramedullary injection of DMEM only (control); the second group received a $5-\mu \mathrm{l}$ injection of $0.5 \mu \mathrm{g}$ ePAM-R (vehicle control); the third, fourth and fifth groups received a $5-\mu$ intramedullary injection of $0.125,0.25$ and $0.5 \mu \mathrm{g}$ ePAM-R, each loaded with $0.5,1.0$ and $2.0 \mu \mathrm{g}$ of apoptin, respectively. A comparative toxicity study utilizing PAM-RG4 was carried out the same way by injecting animals with ePAM-R only, PAM-RG4 only or each vehicle loaded with $2.0 \mu \mathrm{g}$ of apoptin. Animals were evaluated every day for signs of systemic toxicity, and their hindlimb function was routinely assessed until completion of the study.

\section{Efficacy study}

To determine the efficacy in vivo, each of 22 male SD rats was given a $2.5-\mu \mathrm{l}$ intramedullary injection of 100000 C6 glioma cells in DMEM medium on day 0 and were randomized into three experimental groups. On day 5 , the first group received a 7.5- $\mu \mathrm{l}$ injection of DMEM at the same site as the tumor cell injection (sham control group; $n=7$ ); in the second group, at the same site as tumor cell injection, animals received a $7.5-\mu l$ intramedullary injection of PAM-RG4 loaded with control gene (control gene group; $n=7$ ); and in the third group, each animal received a $7.5-\mu l$ injection at the previous tumor cell injection site of PAM-RG4 loaded with $10 \mu \mathrm{g}$ of apoptin (apoptin group; $n=8)$.

\section{Surgical technique}

The surgical technique for intramedullary injection of tumor cells into the adult-rat spinal cord has been described previously. ${ }^{32}$ Briefly, the rats were anesthetized with an intraperitoneal injection $(0.4-0.6 \mathrm{ml})$ of Zoletil
( $50 \mathrm{mg} \mathrm{ml}^{-1}$; Virbac, Carros, France); their backs were shaved, followed by their placement in a sterile field where their backs were prepared with a solution of betadine. The T5 spinous process, easily palpated due to its prominence, was identified and a $2.5-\mathrm{cm}$ longitudinal incision over the dorsal mid-thoracic region was made using a \#10-blade scalpel. The underlying fascia and paraspinal muscles were laterally retracted, the T5 spinous process was removed using rongeurs, and the ligamentum flavum was removed, thereby exposing the intervertebral space. A 26-gauge Hamilton syringe (Hamilton Company, Reno, NV, USA) was inserted through the dorsal T5-T6 intervertebral space. The needle was advanced until it came in contact with the dorsal aspect of the vertebral body, at which point it was retracted $1-2 \mathrm{~mm}$. Penetration of the body of the cord was confirmed by witnessing a lower extremity motor reflex after needle insertion, and the tumor cell suspension was subsequently injected. Following inoculation, wounds were closed with 40 Vicryl (Ethicon, Inc., San Angelo, TX, USA) and analgesia of $0.2 \mathrm{ml}$ of $0.02 \mathrm{mg} \mathrm{ml}^{-1}$ of buprenorphine (Abbott Laboratories, Abbott Park, IL, USA) in saline was administered via intraperitoneal injection.

\section{Locomotion assessment and histopathological analysis}

The BBB locomotor scale, which is a 22-point scale ranging from 0 (no observable hindlimb movement) to 21 (normal locomotion), was employed to assess hindlimb motor function. ${ }^{33}$ Rats were placed into an open-field testing area, allowed to adapt, and were observed for $5 \mathrm{~min}$. Following treatment, animals were tested every other day. After reaching a functional BBB score of less than 5 (frequent or consistent plantar stepping with no coordination or some coordination of the paws with rotation at initial contact and lift off), correlating with the onset of functional paresis as previously defined, ${ }^{32}$ the animals were killed in a $\mathrm{CO}_{2}$ chamber. Spines were immediately removed en bloc, with the resected area comprising the site of injection, and two levels caudal and two levels rostral. All specimens were then placed in $4.0 \%$ formalin in phosphate-buffered saline. Three thoracic spinal sections were cut transversely into $2.0-\mathrm{mm}$ sections and placed onto paraffin wax to be stained using hematoxylin-eosin. To assess the effect of apoptin on tumor growth at the inferred height of its effect, a separate group of sham control$(n=3)$ and apoptin-treated $(n=3)$ animals also underwent histopathological analysis.

\section{Statistical analysis}

Statistical analyses were performed using the IBM SPSS program (SPSS Science, v.19.0, Armonk, NY). Student's $t$-test or ANOVA was used to analyze differences between the groups. The $P$-values less than 0.05 were considered as significant. After reaching the primary end point of a BBB score of less than 5 the threshold for animal killing, survival times were compared among the groups using the Mantel-Cox log-rank test in Kaplan-Meier non-parametric analysis of survival. All data were expressed as mean \pm standard error of the mean (s.e.m.) or mean \pm standard deviation (s.d.).

\section{RESULTS}

Toxicity of apoptin and PAM-RG4, ePAM-R carriers

Animals in this study were randomized to receive an intramedullary free-hand injection of DMEM only, ePAM-R only (vehicle control) or ePAM-R complexed with $0.5,1.0$ or $2.0 \mu$ g apoptin. Animals receiving the vehicle control and all concentrations of apoptin showed no functional deficits (Figure 1a), and exhibited 100\% survival rates for the duration of that part of the study, which lasted for 15 days (data not shown). When utilizing PAM-RG4 loaded with $2.0 \mu \mathrm{g}$ apoptin, results were similar (Figure 1b), building on previous studies incorporating cytotoxicity test results in vitro. ${ }^{34}$

Efficacy of PAM-RG4/apoptin against an intramedullary C6 glioma Animals in this study received an intramedullary injection of C6 glioma cells on day 0 and were randomized to receive on day 5 DMEM injection, control gene treatment or apoptin treatment. Sham control animals had a mean BBB score of $3.71 \pm 1.27$ on day 15 , and a 
median survival of 15 days. Control gene-treated animals had a mean BBB score of $1.29 \pm 0.99$ on day 15 , and a median survival of 13 days. Animals that were treated with apoptin had a mean BBB score of $9.13 \pm 2.17$ on day 15 and a median survival of 19 days (Figure 2). Apoptin-treated animals had significantly higher mean BBB scores than those of sham control animals on day $11(P=0.0258)$, day 15 $(P=0.0338)$, day $17(P=0.0212)$ and day $19\left(P=0.02 ;{ }^{\star} P<0.05\right)$ (Figure 3$)$. For these same time points in the efficacy study, apoptintreated animals exhibited even higher mean BBB scores than those of sham control animals (Figure 3). The Kaplan-Meier survival curve (Figure 4) showing the percentages of animals alive at each particular day of the study shows no significant differences in survival between the apoptin-treated group, the sham control and control gene groups after day 21 ( $P>0.15$, apoptin vs sham; no separate data provided). All rats developed functional paralysis by day 29 , at which time the study was ended.

\section{Histopathological analysis}

Cross-sections of the spinal cords procured from animals in the sham control, control gene and apoptin groups at the end of the study showed similar findings under histopathological analysis: substantial hypercellularity, diffuse infiltration of the spinal cord parenchyma with widespread necrosis, and many areas of hemorrhage (images not shown).

Based on the differences in BBB scores between the experimental groups (Figure 2), it was inferred that the effect of apoptin peaked on day 10. To understand better the effect of apoptin, a separate study of
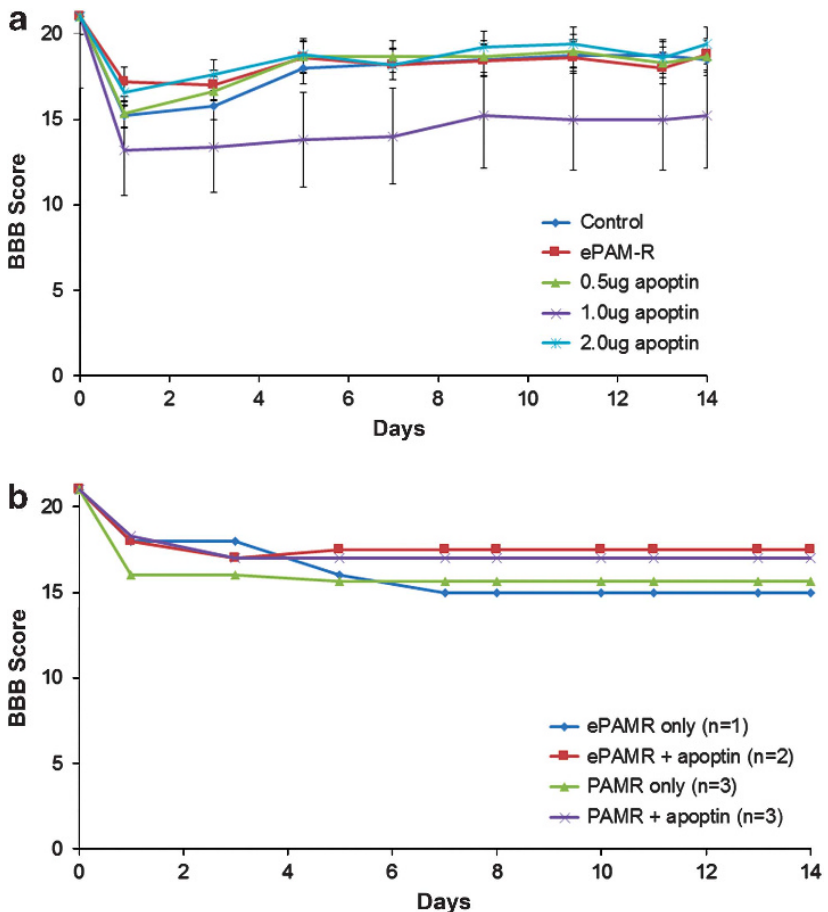

Figure 1 (a) Line graph showing the average BBB scores in the toxicity study of animals injected on day 0 with DMEM media (sham control), ePAM-RG4 (vehicle control) and ePAM-RG4 with $0.5,1.0$ or $2.0 \mu \mathrm{g}$ of apoptin DNA. The study period lasted for 14 days, and no significant morbidity was observed. Error bars are \pm s.e.m. (b) Line graph showing the average $\mathrm{BBB}$ scores in the toxicity study of animals injected on day 0 with ePAM-RG4 (vehicle control), ePAM-RG4 with $2.0 \mu \mathrm{g}$ apoptin, PAM-RG4 (vehicle control), or PAM-RG4 with $2.0 \mu \mathrm{g}$ apoptin. The study period lasted for 14 days, and no significant morbidity was observed. sham- $(n=3)$ and apoptin- $(n=3)$ treated animals were killed on day 10 for hematoxylin-eosin staining. Histopathological analysis on day 10 revealed markedly different findings. Examination of the

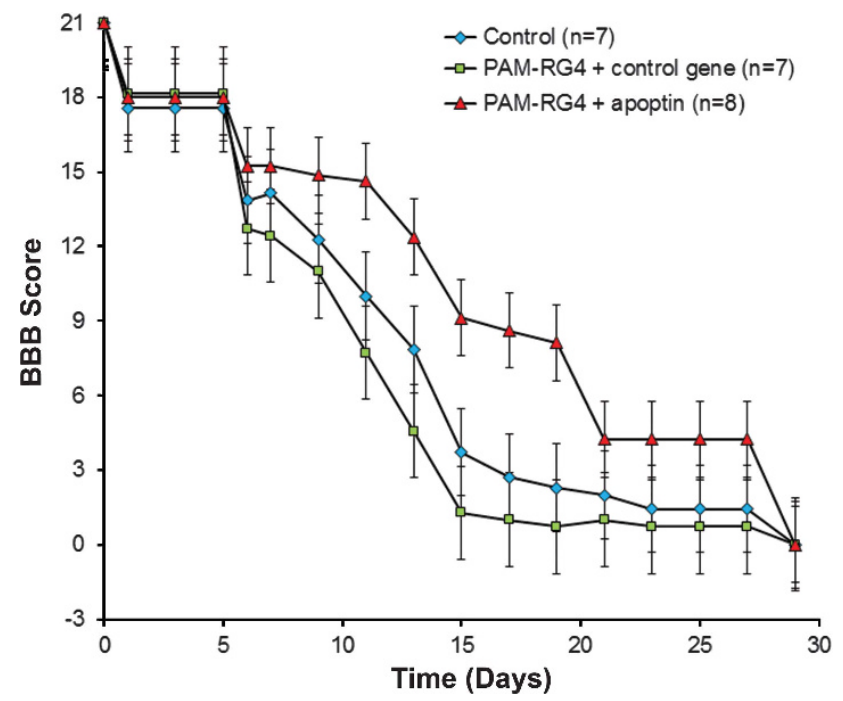

Figure 2 Line graph showing the average BBB score in the efficacy study of animals treated with DMEM (sham control), control gene complexed with PAM-RG4 or apoptin gene complexed with PAM-RG4. After day 5 (treatment day) until the end of the study, apoptin-treated animals consistently had higher functional hindlimb scores than those of sham and control gene animals. The study period lasted until the final animal crossed the killing threshold (day 29). Error bars are \pm s.e.m. The number of animals alive on a particular day of the study can be correlated with the KaplanMeier survival curve of that particular treatment group.

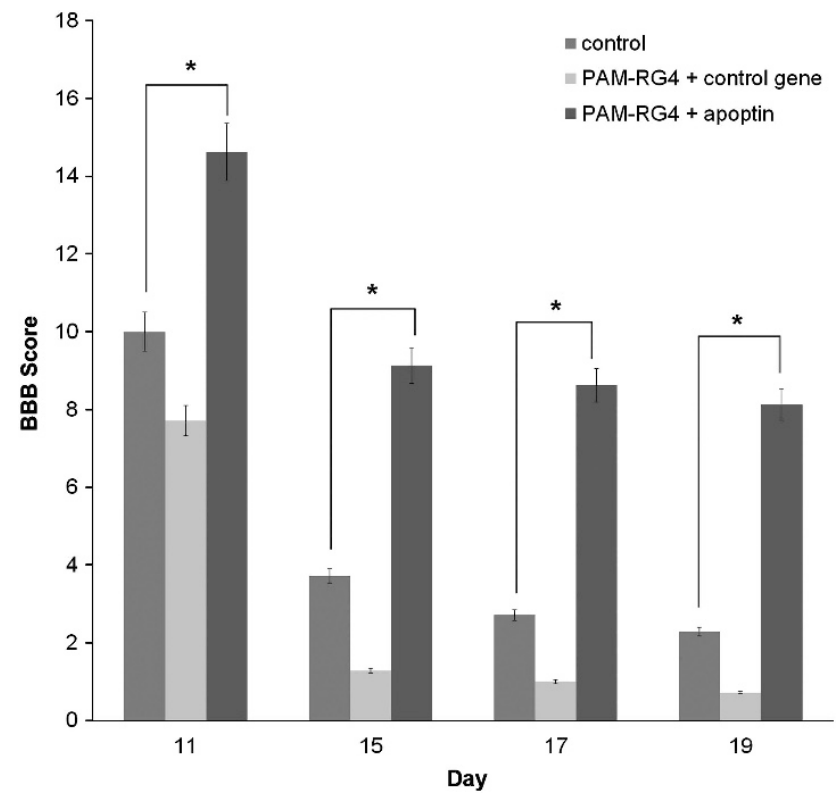

Figure 3 Bar graph representation of the differences in mean BBB scores between the sham control, control gene and apoptin gene treatment groups in the efficacy study. Apoptin-treated animals had a significantly higher BBB score than that of sham controls on day $11(P=0.0258)$, day $15(P=0.0338)$, day 17 $(P=0.0212)$ and day $19(P=0.02) .{ }^{*} P<0.05$ for all. Error bars are \pm s.e.m. The number of animals alive on a particular day of the study can be correlated with the Kaplan-Meier survival curve of that particular treatment group. A full color version of this figure is available at the Spinal Cord journal online. 
micrographs of the sham control animals revealed extensive parenchymal invasion and destruction, diffuse necrosis and scarring, marked hypercellularity, and many concentrated areas of hemorrhage (Figure 5). In contrast, in the apoptin group, the tumor was comparatively much more circumscribed, with less invasion of the spinal cord parenchyma, as some level of normal cytoarchitecture could be seen (Figure 5). Hypercellularity and necrosis were virtually confined to the area of the tumor, and hemorrhaging was seen both

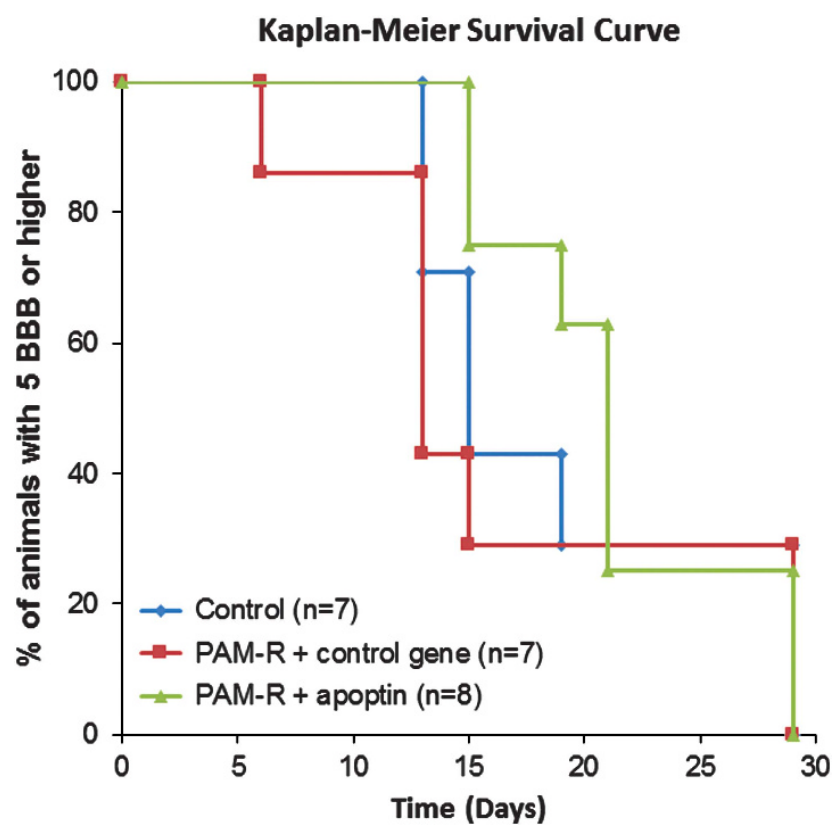

Figure 4 Kaplan-Meier graph showing the onset of paresis (BBB functional score <5). Apoptin-treated animals showed a markedly greater survival over sham control and control gene animals from days 15-20. The study concluded on day 29 (i.e., when the last animal crossed the $<5$ threshold). less frequently and mainly in the tumor mass. There was, however, some evidence of soft tissue involvement.

\section{DISCUSSION}

In the present study, the biocompatibility and efficacy of apoptin as delivered by the dendrimer PAM-RG4 against an experimental intramedullary rat glioma was evaluated. It was found that apoptin can be delivered safely into the rat spinal cord in small doses (from 0.5 to $2 \mu \mathrm{g})$ and larger doses $(10 \mu \mathrm{g}$, as used in the efficacy experiment). Previous in vitro studies showed that ePAM-R is a biodegradable and safer gene delivery carrier than PAM-RG4. ${ }^{31}$ However, since ester bonds, such as those present in ePAM-R, are rather unstable in solution, coupled with our observation that no significant toxicity exists between the use of these two in vivo, PAMRG4 was chosen for practical reasons.

In earlier trials, we saw the effect of apoptin at a dose of $2.0 \mu \mathrm{g}$ was modest, yet not statistically significant (data not shown); as such, the decision was made to load maximally the PAM-RG4 polymer with apoptin. However, in our experience, the rat spinal cord can tolerate a total injection volume of $10 \mu \mathrm{l}$ before sustaining significant damage to hindlimb motor function. Given that a PAM-RG4 polymer:apoptin mass ratio of 4:1 should be observed for optimal apoptin delivery against C6 glioma cells in vitro, ${ }^{34}$ it was decided that $10 \mu \mathrm{g}$ of apoptin would be used. With this increase in concentration came a concomitant increase in injection volume, rising from 5 to $7.5 \mu \mathrm{l}$. Therefore, the injection volume of the $\mathrm{C} 6$ glioma cells was lowered from 5 to $2.5 \mu \mathrm{l}$, so that over the two injections (tumor inoculation and treatment) the total volume injected into the spinal cord was $10 \mu \mathrm{l}$. Animals receiving the treatment with PAM-RG4 loaded with $10 \mu \mathrm{g}$ of apoptin on day 5 showed significantly higher mean BBB scores than those of sham control animals throughout the study (days 11, 15, 17 and 19). Moreover, histopathological analysis of spinal cord cross-sections obtained on day 10 showed a smaller tumor mass, less parenchymal invasion and more preserved cytoarchitecture in apoptin-treated animals compared with the sham control animals. We speculate that apoptin was indeed able to slow tumor progression and preserve hindlimb motor function. Even though, immediately after treatment on day 5, the apoptin group
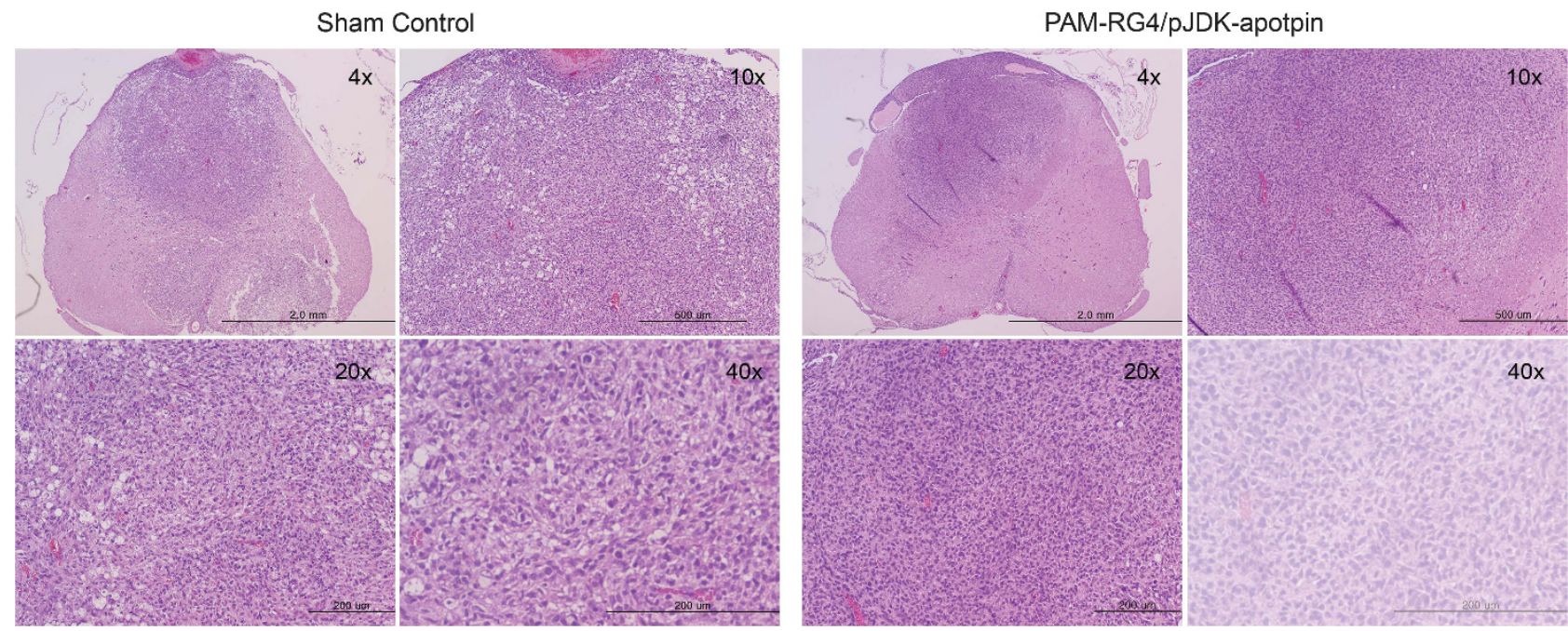

Figure 5 Microphotographs of hematoxylin-eosin-stained cross-sections of the rat spinal cord procured on day 10 that received sham control (DMEM injection) or apoptin treatment on day 5. Extensive invasion of parenchyma, multiple areas of hemorrhage and a large area of necrosis can be appreciated in the sham control animals. Compared with the sham control images, a greater amount of spinal cord cytoarchitecture is preserved, areas of hemorrhage are less prominent, and parenchymal invasion is limited in apoptin-treated animals. 
showed higher survival rates than either of the two control groups, with a markedly higher survival rate from day 11 to day 19 of the study, this difference in survival was not significant. We surmise that, despite the ability of apoptin to slow tumor growth, its effects were nonetheless short-lived, resulting in progressive functional decline.

The result from the present experiment presents a picture of a significant anti-tumor effect manifesting with a preservation of hindlimb motor function, but unchanged mortality from the IMSCT. The present results, coupled with a previous study on the in vivo application of apoptin, ${ }^{34}$ allow a reasonable inference that apoptin has the ability to be tumoricidal, or at the least significantly tumoristatic, if given in large enough doses and able to exert its effects over a longer timeframe. An in vitro experiment found that apoptin combined with etoposide or paclitaxel had an additive cytotoxic effect against human osteosarcoma and prostate tumor cells. ${ }^{25}$ A reasonable next step would be to investigate the efficacy of apoptin at higher doses and in combination with other anti-tumor agents. The present study is, to the best of our knowledge, the first to report on the pre-clinical efficacy of locally delivered apoptin for gene therapy against an animal model of IMSCT. This work utilizes the IMSCT model established earlier ${ }^{32}$ and builds on the use of pre-clinical testing of microsurgical removal, ${ }^{35}$ chemotherapy ${ }^{36,37}$ or gene therapy ${ }^{18,19}$ for its treatment. The availability of a polymer able to deliver nucleic acids to the site of interest was integral to our experiment. PAM-RG4 serves as an ideal vehicle for IMSCT gene therapy because, despite its high charge monomer ratio, it exhibits low cytotoxicity owing to its low molecular weight and its partial protonation under physiological conditions. ${ }^{38}$ In addition, PAM-RG4 has been shown to have enhanced transfection efficiency over its non-arginine parent dendrimer, PAMAM, ${ }^{39}$ and shows low cytotoxicity and improved transfection efficiency in glial cells in mixed cortical culture. ${ }^{40}$

Given the encouraging safety profile of apoptin and its broad spectrum of activity against tumor cells, current studies are focused on its efficient delivery. The delivery of apoptin via adenovirus, ${ }^{41-43}$ baculovirus, ${ }^{44}$ lentivirus-TAT ${ }^{45}$ and HIV-TAT ${ }^{46,47}$ has been reported. Although HIV-TAT delivery of apoptin is suboptimal for use, the other delivery methods show some initial promise; however, concerns remain. Another study has looked at the use of ReGel to deliver paclitaxel against IMSCT. ${ }^{37}$ Yet, given the limitations on gel and polymer delivery of apoptin, owing to injection volume restrictions and cytotoxic effects of gels and polymers at high concentrations, the delivery of apoptin using more natural delivery methods may be indicated. One study has investigated the use of genetically modified neural stem cells to treat spinal cord injury, ${ }^{48}$ and this treatment modality may prove helpful in the delivery of apoptin in the preclinical treatment of IMSCT.

Limitations of this study include the free-hand injection methodology, which may cause animals to sustain damage not associated with the tumor. This was seen in the toxicity study with the animals in the $1.0 \mu \mathrm{g}$-apoptin group. These animals showed a steeper initial decrease in their BBB scores, and were not able to recover fully as their counterparts did. This was an artifact of the free-hand injection procedure, and not due to apoptin toxicity, given that animals subjected to twice as much apoptin showed no deficits or mortality. The only IMSCT study to utilize stereotactic injection of the tumor cells and treatment was outlined by Colak et al. ${ }^{18}$; the surgical methodology employed in that report may serve as a model for future experiments. Another limitation is the use of a non-human cell line, which may result in findings that do not capture fully the tumor microenvironment and response to apoptin. An optimal model would be the injection of human tumor cells into an immunocompromised or a transgenic animal that spontaneously generates glial-specific tumors, although the latter has yet to be reported.

\section{CONCLUSION}

Apoptin can safely be delivered via PAM-RG4 into the adult rat spinal cord in doses up to $10 \mu \mathrm{g}$, where it slows tumor progression, thereby preserving the hindlimb motor function of rats challenged with an intramedullary C6 glioma tumor. These findings support the use of local gene delivery for the treatment of experimental IMSCT, and further studies should be carried out to assess the efficacy of apoptin delivered through different methods and in combination with other chemotherapeutic agents.

\section{DATA ARCHIVING}

There were no data to deposit.

\section{CONFLICT OF INTEREST}

The authors declare no conflict of interest.

\section{ACKNOWLEDGEMENTS}

This study was supported by a grant from the National Research Foundation (NRF) in Korea, funded by the Ministry of Education, Science and Technology (2012K001412, YH), a grant of the Korea Health technology R\&D Project, Ministry of Health \& Welfare, Republic of Korea (A120254), a grant from the Gene Therapy Project of the Ministry of Education, Science and Technology in the Republic of Korea (20110018684, JSP), and the Basic Science Research Program through a NRF grant (2012K001411, JSP). The authors also wish to thank Dr. Se Hoon Kim in the Department of Pathology (Yonsei) for his guidance in processing the specimen.

1 Adams H, Avendano J, Raza SM, Gokaslan ZL, Jallo GI, Quinones-Hinojosa A Prognostic factors and survival in primary malignant astrocytomas of the spinal cord: a population-based analysis from 1973 to 2007. Spine 2012; 37: E727-E735.

2 Parsa AT, Lee J, Parney IF, Weinstein P, McCormick PC, Ames C. Spinal cord and intradural-extraparenchymal spinal tumors: current best care practices and strategies. J Neuro-Oncol 2004; 69: 291-318.

3 Townsend N, Handler M, Fleitz J, Foreman N. Intramedullary spinal cord astrocytomas in children. Pediatr Blood Cancer 2004; 43: 629-632.

4 Van Goethem JWM, van den Hauwe L, Ozsarlak O, De Schepper AMA, Parizel PM. Spinal tumors. Eur J Radiol 2004; 50: 159-176.

5 Bowers DC, Weprin BE. Intramedullary spinal cord tumors. Curr Treat Options Neurol 2003; 5: 207-212.

6 Sandler HM, Papadopoulos SM, Thornton AF, Ross DA. Spinal cord astrocytomas: results of therapy. Neurosurgery 1992; 30: 490-493.

7 Steinbok P, Cochrane DD, Poskitt K. Intramedullary spinal cord tumors in children. Neurosurg Clin N Am 1992; 3: 14

8 McCormick PC, Stein BM. Intramedullary tumors in adults. Neurosurg Clin N Am 1990; 1: 609-630.

9 Minehan KJ, Shaw EG, Scheithauer BW, Davis DL, Onofrio BM. Spinal cord astrocytoma: pathological and treatment considerations. J Neurosurg 1995; 83: 590-595.

10 Osullivan C, Jenkin RD, Doherty MA, Hoffman HJ, Greenberg ML. Spinal cord tumors in children: long term results of combined surgical and radiation treatment. J Neurosurg 1994; 81: 507-512.

11 Schick U, Marquardt G, Lorenz R. Recurrence of benign spinal neoplasms. Neurosurg Rev 2001; 24: 20-25.

12 Shirato H, Kamada T, Hida K, Koyanagi I, Iwasaki Y, Miyasaka K et al. The role of radiotherapy in the management of spinal cord glioma. Int J Radiat Oncol 1995; 33: 323-328.

13 Balmaceda C. Chemotherapy for intramedullary spinal cord tumors. J Neuro-Oncol 2000; 47: 293-307.

14 Doireau V, Grill J, Zerah M, Lellouch-Tubiana A, Couanet D, Chastagner P et al. Chemotherapy for unresectable and recurrent intramedullary glial tumors in children. Br J Cancer 1999; 81: 835-840.

15 Fouladi M, Hunt DL, Pollack IF, Dueckers G, Burger PC, Becker LE et al. Outcome of children with centrally reviewed low-grade gliomas treated with chemotherapy with or without radiotherapy on Children's Cancer Group high-grade glioma study CCG-945. Cancer Am Cancer Soc 2003; 98: 1243-1252.

16 Henson JW, Thornton AF, Louis DN. Spinal cord astrocytoma: response to PCV chemotherapy. Neurology 2000; 54: 518-520.

17 Mora J, Cruz O, Gala S, Navarro R. Successful treatment of childhood intramedullary spinal cord astrocytomas with irinotecan and cisplatin. Neuro-Oncology 2007; 9: 39-46. 
18 Colak A, Goodman JC, Chen SH, Woo SLC, Grossman RG, Shine HD. Adenovirus mediated gene-therapy for experimental spinal cord tumors: tumoricidal efficacy and functional outcome. Brain Res 1995; 691: 76-82.

19 Won YW, Kim KM, An SS, Lee M, Ha Y, Kim YH. Suicide gene therapy using reducible poly (oligo-D-arginine) for the treatment of spinal cord tumors. Biomaterials 2011; 32: 9766-9775.

20 Noteborn MHM, Deboer GF, Vanroozelaar DJ, Karreman C, Kranenburg O, Vos JG et al. Characterization of cloned chicken anemia virus DNA that contains all elements for the infectious replication cycle. J Virol 1991; 65: 3131-3139.

21 Noteborn MHM, Todd D, Verschueren CAJ, HWFM Degauw, Curran WL, Veldkamp S et al. A single chicken anemia virus protein induces apoptosis. J Virol 1994; 68: 346-351.

22 Danen-vanOorschot AAAM, Fischer DF, Grimbergen JM, Klein B, Zhuang SM Falkenburg JHF et al. Apoptin induces apoptosis in human transformed and malignant cells but not in normal cells. Proc Natl Acad Sci USA 1997; 94: 5843-5847.

23 Noteborn MHM, Danen-van Oorschot AAAM, Van der Eb AJ. The apoptin gene of chicken anemia virus in the induction of apoptosis in human tumorigenic cells and in gene therapy of cancer. In: Boulikas T (ed.). Gene Therapy Mol Biol 1998; 1: 399-406.

24 Lian H, Jin NY, Li X, Mi ZQ, Zhang JM, Sun LL et al. Induction of an effective antitumor immune response and tumor regression by combined administration of IL-18 and apoptin. Cancer Immunol Immun 2007; 56: 181-192.

25 Olijslagers SJ, Zhang YH, Backendorf C, Noteborn MHM. Additive cytotoxic effect of apoptin and chemotherapeutic agents paclitaxel and etoposide on human tumour cells. Basic Clin Pharmacol 2007; 100: 127-131.

26 Oorschot AAAMD, Zhang Y, Erkeland SJ, Fischer DF, van der Eb AJ, Noteborn MHM The effect of Bcl-2 on Apoptin in 'normal' vs transformed human cells. Leukemia 1999; 13: S75-S77.

27 Zhuang SM, Shvarts A, Vanormondt H, Jochemsen AG, Vandereb AJ, Noteborn MHM. Apoptin, a protein derived from chicken anemia virus, induces p53-independent apoptosis in human osteosarcoma cells. Cancer Res 1995; 55: 486-489.

28 Maddika S, Mendoza FJ, Hauff K, Zamzow CR, Paranjothy T, Los M. Cancer-selective therapy of the future: apoptin and its mechanism of action. Cancer Biol Ther 2006; 5: 10-19.

29 Maddika S, Booy EP, Johar D, Gibson SB, Ghavami S, Los M. Cancer-specific toxicity of apoptin is independent of death receptors but involves the loss of mitochondrial membrane potential and the release of mitochondrial cell-death mediators by a Nur77dependent pathway. J Cell Sci 2005; 118: 4485-4493.

30 Lin BZ, Kolluri SK, Lin F, Liu W, Han YH, Cao XH et al. Conversion of Bcl-2 from protector to killer by interaction with nuclear orphan receptor Nur77/TR3. Cell 2004; 116: $527-540$.

31 Nam HY, Nam K, Hahn HJ, Kim BH, Lim HJ, Kim HJ et al. Biodegradable PAMAM ester for enhanced transfection efficiency with low cytotoxicity. Biomaterials 2009; 30: 665-673.

32 Caplan J, Pradilla G, Hdeib A, Tyler BM, Legnani FG, Bagley CA et al. A novel model of intramedullary spinal cord tumors in rats: functional progression and histopathological characterization. Neurosurgery 2006; 59: 193-199.

33 Basso DM, Beattie MS, Bresnahan JC. Graded histological and locomotor outcomes after spinal cord contusion using the NYU weight-drop device versus transection. Exp Neurol 1996; 139: 244-256.

34 An S, Nam K, Choi S, Bai CZ, Lee Y, Park J. Nonviral gene therapy in vivo with PAM-RG4/apoptin as a potential brain tumor therapeutic. Int J Nanomed 2013; 8 821-834.
35 Pennant WA, Sciubba DM, Noggle JC, Tyler BM, Tamargo RJ, Jallo GI. Microsurgica removal of intramedullary spinal cord gliomas in a rat spinal cord decreases onset to paresis, an animal model for intramedullary tumor treatment. Child Nerv Syst 2008. 24: 901-907.

36 Hayashi K, Yamauchi K, Yamamoto N, Tsuchiya H, Tomita K, Bouvet M et al. A color-coded orthotopic nude-mouse treatment model of brain-metastatic paralyzing spinal cord cancer that induces angiogenesis and neurogenesis. Cell Proliferat 2009, 42: $75-82$

37 Tyler BM, Hdeib A, Caplan J, Legnani FG, Fowers KD, Brem H et al. Delayed onset of paresis in rats with experimental intramedullary spinal cord gliosarcoma following intratumoral administration of the paclitaxel delivery system OncoGel Laboratory investigation. J Neurosurg Spine 2012; 16: 8.

38 Fischer D, Li YX, Ahlemeyer B, Krieglstein J, Kissel T. In vitro cytotoxicity testing of polycations: influence of polymer structure on cell viability and hemolysis. Biomaterials 2003; 24: 1121-1131.

39 Choi JS, Nam K, Park J, Kim JB, Lee JK, Park J. Enhanced transfection efficiency of PAMAM dendrimer by surface modification with L-arginine. J Control Release 2004; 99: 445-456.

40 Kim JB, Choi JS, Nam K, Lee M, Park JS, Lee JK. Enhanced transfection of primary cortical cultures using arginine-grafted PAMAM dendrimer, PAMAM-Arg. J Control Release 2006; 114: 110-117.

41 Pietersen AM, van der Eb MM, Rademaker HJ, van den Wollenberg DJ, Rabelink MJ, Kuppen PJ et al. Specific tumor-cell killing with adenovirus vectors containing the apoptin gene. Gene Ther 1999; 6: 882-892.

42 Xiao L, Yan L, Zhongmei W, Chang L, Huijun L, Mingyao T et al. Potent anti-tumo effects of a dual specific oncolytic adenovirus expressing apoptin in vitro and in vivo. Mol Cancer 2010; 9: 10.

43 Zhang KJ, Qian J, Wang SB, Yang Y. Targeting gene-viro-therapy with AFP driving apoptin gene shows potent antitumor effect in hepatocarcinoma. J Biomed Sci 2012; 19: 20.

44 Pan YF, Fang LR, Fan HY, Luo R, Zhao Q, Chen HC et al. Antitumor effects of a recombinant pseudotype baculovirus expressing Apoptin in vitro and in vivo. Int $J$ Cancer 2010; 126: 2741-2751.

$45 \mathrm{Ma}$ JL, Han SX, Zhao J, Zhang D, Wang L, Li YD et al. Systemic delivery of lentivirusmediated secretable TAT-apoptin eradicates hepatocellular carcinoma xenografts in nude mice. Int J Oncol 2012; 41: 1013-1020.

46 Guelen L, Paterson H, Gaken J, Meyers M, Farzaneh F, Tavassoli M. TAT-apoptin is efficiently delivered and induces apoptosis in cancer cells. Oncogene 2004; 23: 1153-1165.

47 Maddika S, Wiechec E, Ande SR, Poon IK, Fischer U, Wesselborg S et al. Interaction with PI3-kinase contributes to the cytotoxic activity of apoptin. Oncogene 2008; 27: 3060-3065.

48 Jin HL, Pennant WA, Lee MH, An SS, Kim HA, Liu ML et al. Neural stem cells modified by a hypoxia-inducible VEGF gene expression system improve cell viability under hypoxic conditions and spinal cord injury. Spine 2011; 36: 857-864.

(c) (1) $\odot$ This work is licensed under a Creative Commons Attribution-NonCommercial-NoDerivs 3.0 Unported License. To view a copy of this license, visit http://creativecommons. org/licenses/by-nc-nd/3.0/ 